\title{
PENGARUH DEBIT AIR TERHADAP TEGANGAN OUTPUT PADA PEMBANGKIT LISTRIK TENAGA PICO HYDRO
}

\author{
Muhammad Luthfi Hakim ${ }^{1}$, Nurhening Yuniarti ${ }^{2}$, Sukir $^{3}$, Eko Swi Damarwan ${ }^{4}$ \\ ${ }^{1,2,3,4}$ Fakultas Teknik, Universitas Negeri Yogyakarta \\ Email: luthfihakim93@uny.ac.id
}

\begin{abstract}
Renewable energy is an alternative energy for the future. The potential for renewable energy in Indonesia is huge, one of which is the Hydroelectric Power Plant (PLTS). Power values for under $500 \mathrm{~W}$ are included in the pico hydro category. The river flow in every village in Indonesia has great potential in developing the pico hydro Power Plant. This study aims to determine the effect of water discharge on DC voltage in pico hydro power plants. The installation in this plant consists of; water inlet (inlet), turbine, generator, voltage indicator, and outlet (output). This research was conducted experimentally and carried out in Sungai Pelang, Sleman, Yogyakarta. The results showed that the higher the inlet (outlet) and the value of the outlet (outlet) the greater the value of water discharge. The greater the value of water discharge, the greater the voltage generated. Discharge values and elevation differences greatly affect the pico hydro output voltage.
\end{abstract}

Keywords : Pico hydro, Turbine, Generator, Discharge, and Voltage.

\begin{abstract}
ABSTRAK
Energi terbarukan merupakan energi alternatif untuk masa depan. Potensi akan energi terbarukan di Indonesia sangat besar, salah satunya adalah Pembangkit Listrik Tenaga Air (PLTS). Nilai daya untuk di bawah $500 \mathrm{~W}$ merupakan masuk kategori pico hydro. Aliran sungai yang ada disetiap kampung di Indonesia menjadi potensi besar dalam mengembangkan Pembangkit Listrik Tenaga pico hydro. Penelitian ini bertujuan untuk mengetahui pengaruh debit air terhadap tegangan DC pada pembangkit listrik tenaga pico hidro. Instalasi pada pembangkit ini terdiri dari; saluran masuk air (inlet), turbin, generator, indikator tegangan, dan saluran buang air (output). Penelitian ini dilakukan secara eksperimen dan dilaksanakan di Sungai Pelang, Sleman, Yogyakarta. Hasil penelitian menunjukkan bahwa semakin tinggi saluran masuk (inlet) dan nilai saluran buang (outlet) nilai debit air akan semakin besar. Semakin besar nilai debit air maka semakin besar Tegangan yang dihasilkan. Nilai debit dan perbedaan elevasi sangat berpengaruh terhadap tegangan output pico hydro.
\end{abstract}

Kata kunci: Pico hydro, Turbin, Generator, Debit, dan Tegangan.

\section{PENDAHULUAN}

Dalam beberapa tahun terakhir, perkembangan pembangkit listrik yang menggunakan sumber energi terbarukan meningkat untuk melindungi lingkungan dan mengurangi efek rumah kaca sebagai akibat dari penggunaan bahan bakar fosil. Inisiatif ini telah dilakukan di negara-negara maju dan dijadikan kebijakan untuk memberikan dorongan penelitian dan pengembangan bentukbentuk alternatif pembangkit listrik (Sergio,
2016). Beberapa pembangkit yang bekerja dengan sumber energi terbarukan yang paling umum telah dikembangkan adalah: air, matahari, angin dan dari biomassa.

Saat ini, para peneliti memberikan masukan tentang pentingnya energi berkelanjutan, terutama telah memaparkan bahwa bahan bakar fosil mahal dan karena efek negatif yang besar terhadap dampak lingkungan. Energi terbarukan menghadirkan solusi yang paling cocok untuk mendapatkan koneksi yang bagus antara energi terbarukan 
dan pembangunan berkelanjutan (Elbatran, 2015). Peran energi terbarukan telah didefinisikan sebagai peranan penting bagi masalah lingkungan global. Pembangkit listrik tenaga air adalah contoh tipe efisien dari energi terbarukan dan aplikasi potensial untuk pembangkit listrik di masa depan. Oleh karena itu, pembangkit listrik tenaga air tidak menghasilkan emisi udara tetapi dalam banyak kasus memiliki efek buruk pada kualitas air, habitat satwa liar dan mencegah migrasi ikan, tetapi baru-baru ini, teknologi baru seperti sistem tenaga vortex air gravitasi dapat mengatasi masalah ini. Hydropower saat ini merupakan sumber energi terbarukan yang paling aman, efisien dan andal, berdasarkan penelitian-penelitian yang dilakukan.

Energi terbarukan menjadi alternatif energi untuk masa depan di seluruh dunia. Sifat dari energi terbarukan yang bisa dipakai selamanya dan tidak pernah habis menjadi faktor utama dipilih menjadi energi masa depan. Salah satu contohnya adalah energi listrik yang dihasilkan oleh Pembangkit Listrik Tenaga Air (PLTA). PLTA sebagai sumber energi terbarukan memberi masyarakat manfaat sebagai pengganti bahan bakar fosil. Sumber energi yang dihasilkan oleh air memiliki potensi yang besar untuk dikembangkan di Indonesia. Di negeri yang memiliki wilayah sebagian besar daerah perairan ini sangat cocok dalam penerapan energi listrik pembangkit tenaga mikro hidro. Menurut penelitian yang dilakukan oleh Rumampuk (2013) luas wilayah daratan Indonesia $\pm 2.012 .402 \mathrm{~km}^{2}$ dan luas perairannya $\pm 5.877 .879 \mathrm{~km}^{2}$. Dapat disimpulkan bahwa luas wilayah indonesia $2 / 3$ nya berupa daerah perairan.

PLTA tergolong murah dan memiliki sitem kerja yang sederhana. Sehingga belakangan sistem pembangkit ini mulai banyak dikembangkan di Indonesia. Pada umumnya hasil output energi listrik yang dihasilkan dari PLTA dapat digunakan untuk menghidupkan penerangan jalan. Banyak referensi yang bisa digunakan dalam pembuatan sistem ini, sehingga dari semua kalangan bisa membuat dan memasang alat ini di sungai-sungai kecil.

Energi listrik merupakan kebutuhan primer di Indonesia, tetapi penyediaan energi listrik masih belum merata di Indonesia. Masih banyak desa-desa di pedalaman yang belum terjangkau aliran listrik (Juwito, 2012). Sehingga alternatif energi listrik yang dapat dikembangkan di desa tersebut adalah salah satunya dengan membangun sistem PLTA sederhana. Menurut penelitian (International Energy Agency, 2014) sejak tahun 2012 tenaga air berkontribusi $16,2 \%$ terhadap total pembangkit listrik global.

Berdasarkan besar kapasitasnya PLTA dibagi menjadi beberapa bagian, diantaranya yang sering kita jumpai skala kecil adalah Pembangkit Listrik Tenaga Mikrohidro yaitu dengan kapsitas daya sebesar $0.5-100 \mathrm{KW}$ dan Pembangkit Listrik Tenaga pico hydro yaitu sebesar <500 W (Lahimer, 2012). Pada penelitian ini akan dipilih Pembangkit Listrik Tenaga pico hydro sebagai topik penelitian, karena aplikasi dari pico hydro adalah untuk head yang rendah. Sehingga sangat cocok dengan kondisi lapangan penelitian, yaitu di sungai Pelang, Sleman, Yogyakarta.

Tabel 1 menunjukkan jenis pembangkit listrik tenaga air berdasarkan kapasitas yang dihasilkan dibagi menjadi 6 jenis (Benedicto, 2018).

Tabel 1. Jenis pembangkit listrik tenaga air berdasarkan kapasitas yang dihasilkan

\begin{tabular}{ll}
\hline Pembangkit Listrik & Kapasitas \\
\hline Large-Hydro & Lebih dari 100MW \\
Medium-Hydro & $15-100 \mathrm{MW}$ \\
Small-Hydro & $1-15 \mathrm{MW}$ \\
Mini-Hydro & $100 \mathrm{~kW}-1 \mathrm{MW}$ \\
Micro-Hydro & Hingga 100 kW \\
Pico-Hydro & Dibawah 5kW \\
\hline
\end{tabular}

Konsep dasar dari desain sederhana pico hydro dapat dilihat pada Gambar 1. 


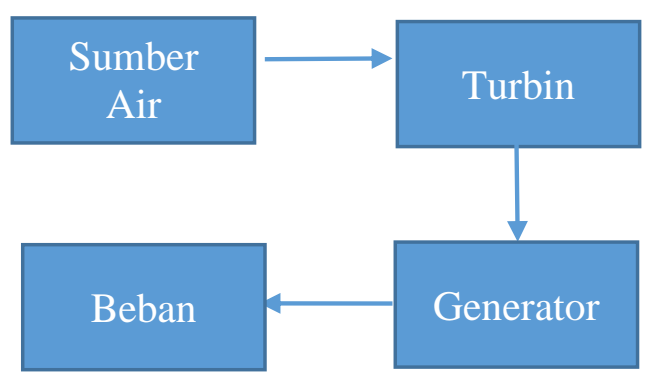

Gambar 1 Desain sederhana pico hydro.

Sumber mata air memiliki peran yang sangat penting dalam sebuah desain pembangkit listrik. Debit aliran dan perbedaan elevasi memiliki peran dalam penentuan hasil akhir dari energi listrik yang dihasilkan, sehingga pemilihan sumber air yang akan digunakan sebagai tempat pembangkit listrik pico hydro harus melalui perhitungan yang matang.
Sumber air akan dihubungkan dengan pipa untuk menuju turbin, Aliran air di dalam pipa memiliki potensi energi kinetik untuk memutar turbin.

Jenis turbin yang digunakan pada penelitian ini adalah turbin vortex. Prinsip kerja dari turbin ini adalah mengubah tenaga air menjadi gaya rotasi untuk menggerakkan generator. Memilih turbin yang tepat sangat penting karena efisiensi keseluruhan sistem bergantung pada bagian ini. Gambar 2 menunjukkan desain pemasangan dari turbin vortex. Turbin ditransmisikan dengan generator, sehingga putaran yang dihasilkan oleh turbin dapat memutarkan generator.

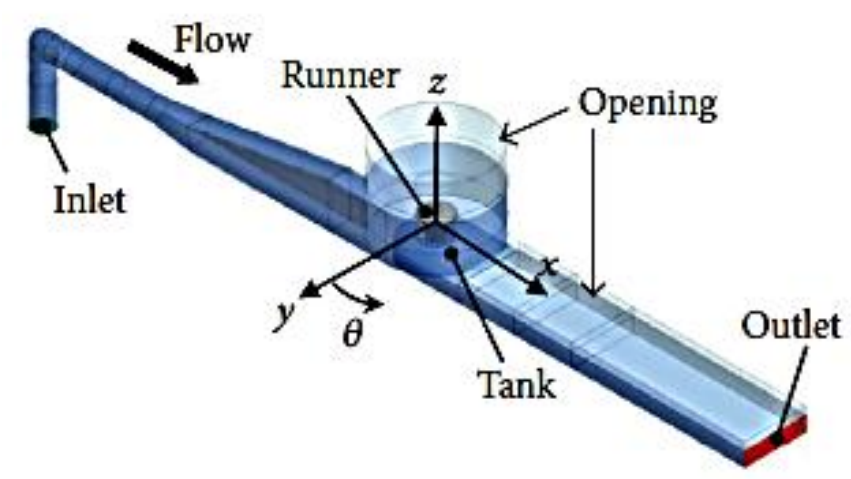

Gambar 2. Desain Pemasangan Turbin Vortex (Nishi, 2017)

Generator mengubah energi mekanik menjadi listrik, generator DC digunakan pada penelitian ini. Generator bekerja berdasarkan prinsip induksi elektromagnetik, yaitu dengan memutar suatu kumparan dalam medan magnet sehingga timbul GGL (Gaya Gerak Listrik) induksi.

Energi listrik yang dihasilkan oleh generator digunakan untuk menghidupkan lampu. Dalam Penelitian ini beban yang digunakan sebagai media adalah lampu bohlam. Dalam tahap perancangan penelitian ini ada banyak faktor yang menentukan kelayakan dan pencapaian sistem. Diantaranya adalah:

a. Jumlah daya yang tersedia dari aliran air di dalam pipa. Ini tergantung pada tekanan air, jumlah air yang tersedia, dan rugi gesekan pada pipa.

b. Jenis turbin dan ketersediaan dan kapasitas generator yang dibutuhkan.

c. Jenis dan kapasitas beban listrik yang akan dipasok oleh sistem pico-hydro.

d. Biaya pembuatan dan pengoperasian sistem.

Beberapa faktor yang memiliki pengaruh terhadap daya output yang dihasilkan oleh pico hydro adalah diantaranya; debit aliran, elevasi (perbedaan ketinggian) dan jenis turbin yang digunakan. Debit aliran menjadi fokus utama pada penelitian kali ini. Diharapkan dengan penelitian adanya penelitian ini, masyarakat di Yogyakarta dapat mengembangkan potensi 
sungai yang ada disekitar Yogyakarta sebagai alternatif pembangkit tenaga listrik.

Jenis turbin yang biasa digunakan untuk perbedaan elevasi yang rendah adalah turbin vortex grafitasi. Prinsip kerja dari turbin ini adalah memasukkan aliran air ke dalam tangki dan menggunakan pusaran gravitasi yang dihasilkan ketika air mengalir dari bagian bawah tangki sehingga energi listrik dapat dihasilkan (Nishi, 2017). Keuntungan dari turbin vortex grafitasi adalah menghasilkan listrik dari elevasi dan laju aliran yang rendah dengan struktur yang relatif sederhana.

Turbin pico bekerja dengan prinsip yang sama dengan turbin tenaga air lainnya dan memiliki persamaan tenaga air yang sama yaitu (Purohit, 2008);

$$
P=\eta \times \rho \times g \times Q \times h
$$

Dimana $P$ adalah tenaga mekanis yang dihasilkan di poros turbin (watt). $\eta$ adalah effisiensi dari turbin (\%), $\rho$ adalah massa jenis dari air $\left(\mathrm{kg} / \mathrm{m}^{3}\right), g$ adalah kecepatan gravitasi bumi yaitu $\left(g=9,81 \mathrm{~m} / \mathrm{s}^{2}\right) \quad Q$ adalah laju aliran volume yang melewati turbin $\left(\mathrm{m}^{3} / \mathrm{s}\right)$, dan adalah elevasi antara turbin dan lairan air (m).

Hydro Power dihasilkan dari energi dalam sumber daya air yang mengalir bebas dan diubah menjadi energi mekanik. Energi ini dapat digunakan secara langsung atau dapat dikonversi menjadi listrik menggunakan generator.

\section{METODE}

Ilustrasi dari perlengkapan eksperimen penelitian ini dapat dilihat pada Gambar 3. Instalasi pikohidro secara sederhana dapat dijelaskan pada Gambar 3.

Secara sederhana prinsip kerja alat tersebut adalah energi mekanik yang dihasilkan oleh air akan memutarkan turbin, kemudian turbin dihubungkan dengan shaft menuju generator untuk diubah menjadi energi listrik. Kemudian akan terbaca pada indikator besar tegangan DC yang dihasilkan oleh alat tersebut.

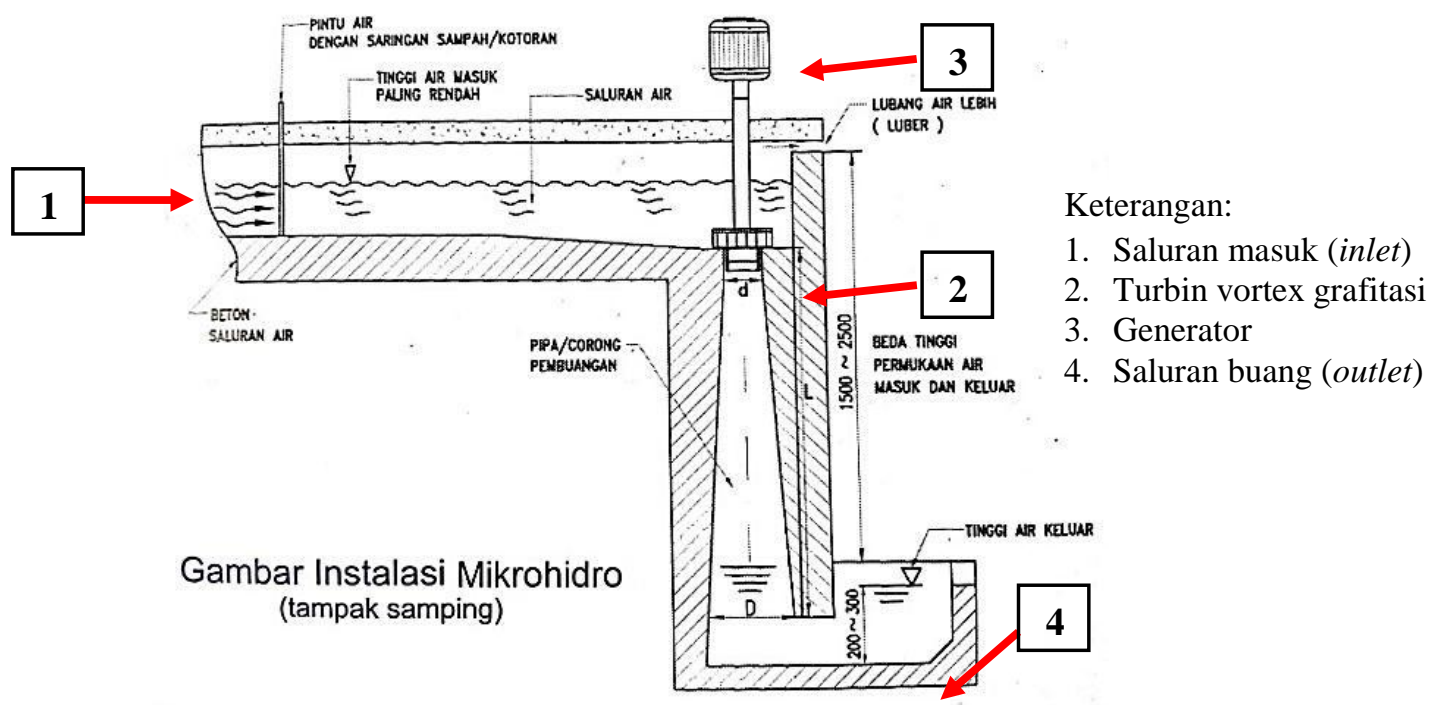

Gambar 3. Instalasi Pikohidro

Pada penelitian ini data yang akan diambil adalah variasi ketinggian masuk air di saluran masuk dan debit aliran. Diharapkan mendapat hasil mengenai pengaruh debit aliran terhadap tegangan output yang dihasilkan. Data yang akan diambil pada penelitian ini dapat dilihat pada Tabel 2. Penelitian ini dilakukan di Sungai Pelang, sleman, Yogyakarta. 
Tabel 2. Data Penelitian

\begin{tabular}{ccc}
\hline $\begin{array}{c}\text { Tinggi saluran } \\
\text { Buang }(\mathrm{cm})\end{array}$ & $\begin{array}{c}\text { Tinggi saluran } \\
\text { Masuk }(\mathrm{cm})\end{array}$ & $\begin{array}{c}\text { Tegangan } \\
\text { DC }(\mathrm{V})\end{array}$ \\
\hline & 17 & \\
25 & 13 & \\
& 10 & \\
& 7 & \\
& 17 \\
30 & 13 & \\
& 10 \\
& 7 \\
\hline & 17 \\
& 13 \\
& 10 \\
\end{tabular}

\section{HASIL DAN PEMBAHASAN}

Debit merupakan hasil bagi antara volume masuk dan waktu. Debit air memiliki peran yang sangat penting dalam sebuah pembangkit listrik tenaga pico hydro, karena semakin besar debit air yang dihsilkan maka akan semakin besar energi mekanik yang dihasilkan untuk memutarkan turbin. Nilai debit pada penelitian ini dapat dilihat pada Tabel 3.
Dari tabel tersebut dapat disimpulkan bahwa semakin tinggi saluran masuk (inlet) nilai debit air akan semakin besar. Begitu juga ketika nilai saluran buang (outlet) semakin besar maka nilai debit air juga akan semakin besar.

Tabel 3. Nilai Debit Air

\begin{tabular}{ccc}
\hline $\begin{array}{c}\text { Tinggi saluran } \\
\text { Buang }(\mathrm{cm})\end{array}$ & $\begin{array}{c}\text { Tinggi saluran } \\
\text { Masuk }(\mathrm{cm})\end{array}$ & $\begin{array}{c}\text { Debit } \\
\left(\mathrm{cm}^{3} / \mathrm{s}\right)\end{array}$ \\
\hline \multirow{2}{*}{25} & 17 & 27200 \\
& 13 & 24960 \\
& 10 & 24000 \\
30 & 7 & 13500 \\
\hline \multirow{3}{*}{35} & 17 & 38800 \\
& 13 & 36000 \\
& 10 & 35200 \\
& 7 & 28700 \\
\hline & 17 & 60600 \\
& 13 & 57600 \\
& 10 & 48000 \\
\end{tabular}

Gambar 4 menunjukkan nilai debit air pada setiap ketinggian saluran masuk, dimana semakin tinggi saluran masuk air maka nilai debit juga akan semakin besar.

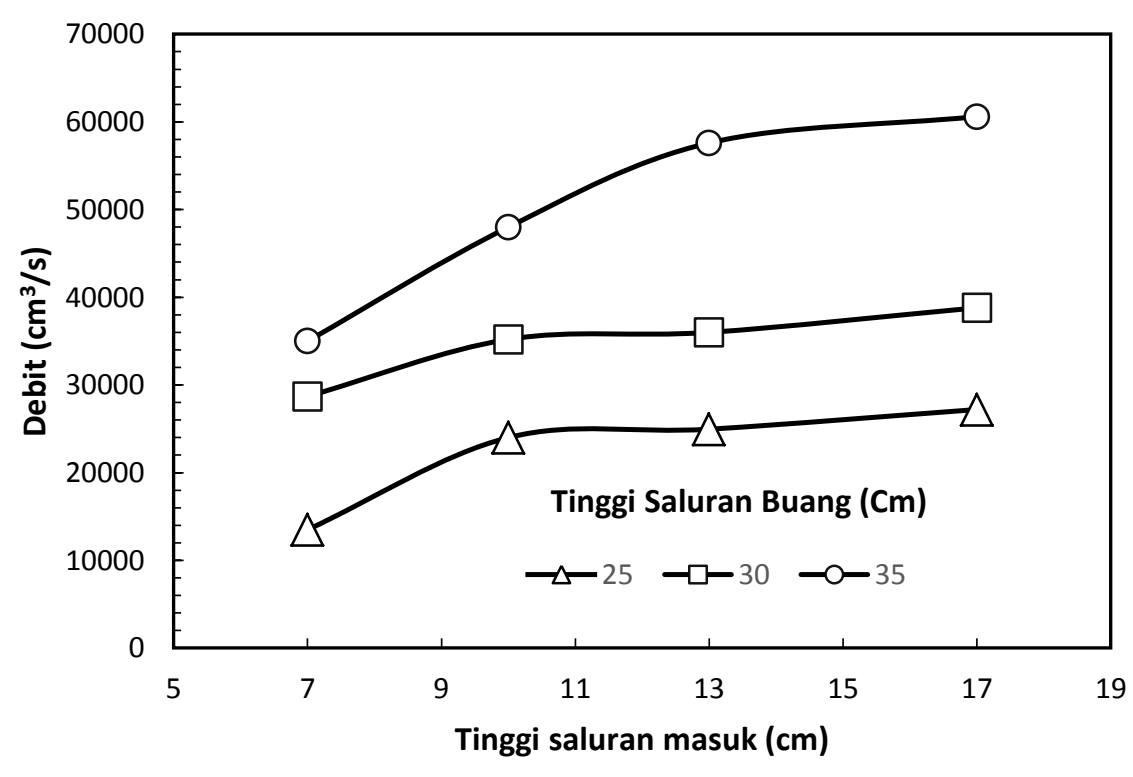

Gambar 4. Nilai Debit pada setiap tinggi saluran masuk

Penelitian ini menghasilkan nilai tegangan DC pada setiap percobaan. Tegangan tersebut terbaca pada indikator yang ada dalam generator. Hasil dari pembacaan indikator pada generator dapat dilihat pada Gambar 5. 


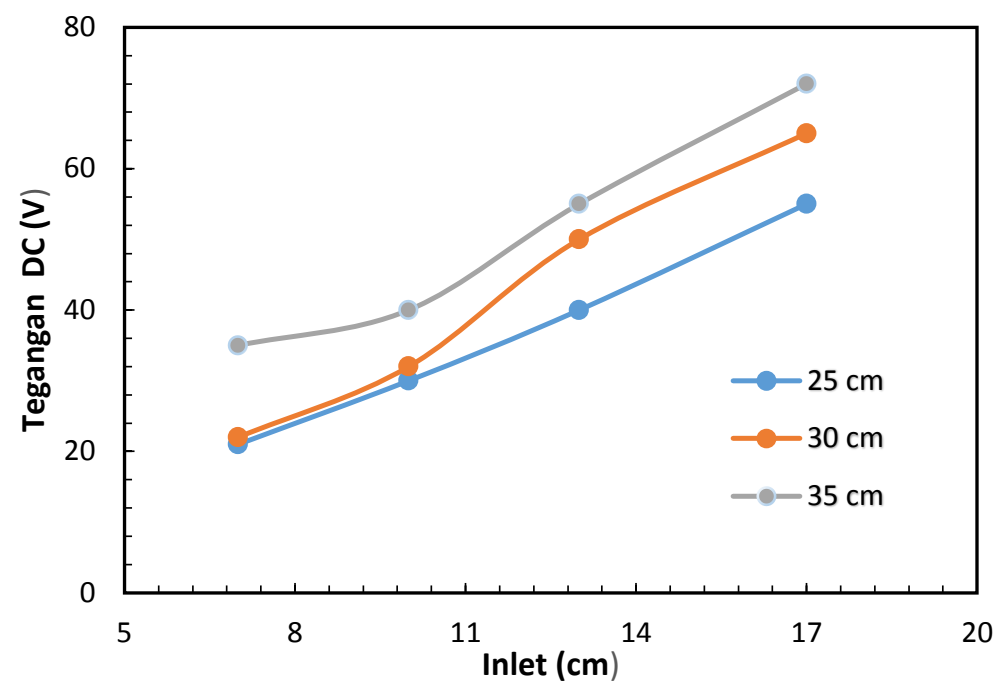

Gambar 5. Nilai Tegangan DC pada Variasi Ketinggian Outlet

Dari grafik tersebut dapat disimpulkan bahwa nilai tegangan DC akan semakin besar ketika ketinggian saluran masuk (inlet) semakin besar. Nilai tegangan DC akan semakin besar pada ketinggian saluran buang (outlet) yang semakin tinggi. Dapat disimpulkan bahwa nilai debit dan perbedaan elevasi akan berpengaruh terhadap tegangan yang dihasilkan, dimana semakin besar debit maka semakin besar tegangan yang dihasilkan. Kondisi tersebut didukung juga oleh faktor teoritis yaitu semakin besar debit maka semakin besar energi yang dihasilkan oleh air, sehingga energi mekanik yang digunakan untuk memutar turbin juga akan semakin besar.

\section{SIMPULAN}

Dari hasil penelitian tentang pengaruh debit air terhadap tegangan DC pada pembangkit listrik tenaga pico hydro dapat diambil kesimpulan bahwa semakin tinggi saluran masuk (inlet) dan nilai saluran buang (outlet) nilai debit air akan semakin besar. Semakin besar nilai debit air maka semakin besar Tegangan yang dihasilkan. Nilai debit dan perbedaan elevasi sangat berpengaruh terhadap tegangan output pico hydro.

\section{DAFTAR RUJUKAN}

A. A. Lahimer, M. A. Alghoul , K. Sopian , N Amin, N Asim, and M. I. Fadhel. 2012. Research and development aspects of pico-hydro power. Renewable and Sustainable Energy Reviews 16 (2012) 5861-5878

A. F. Juwito, S. Pramonohadi, dan T. Haryono. 2012. Optimalisasi Energi Terbarukan pada Pembangkit Tenaga Listrik dalam Menghadapi Desa Mandiri Energi di Margajaya. Jurnal Ilmiah Semesta Teknika. Vol. 15, No. 1, 22-34

A. H. Elbatrana, Mohamed Walid AbdelHameda, O. B. Yaakobb, Yasser M. Ahmed, M. Arif Ismail. 2015. Hydro Power and Turbine Systems Reviews. Jurnal Teknologi (Sciences \& Engineering) 74:5 (2015), 83-90

Benedicto N. Fortaleza, Ronnie O. Serfa Juan and Lean Karlo S. Tolentino. 2018. IoTbased Pico-Hydro Power Generation System using Pelton Turbine. Journal of Telecommunication, Electronic and Computer Engineering. e-ISSN: 22898131 Vol. 10 No. $1-4$

Purohit P. Small hydro power projects under clean development mechan- ism in India: a preliminary assessment. Energy Policy 2008;36(6):2000-15. 
Rumampuk, R.. 2013. Hak atas pengelolaan kawasan pesisir di Provinsi Sulawesi Utara. Lex et Societatis. I (5): 54-63.

Sergio Antonio Zarate-Orrego, Gerardo Andrés Torres-Casierra, Efraín Baldemar del Risco-Moreno. 2016. Horizontal vortex single chamber hydroturbine. Revista Facultad de Ingeniería, Universidad de
Antioquia, International Energy Agency, Key World Energy Statistics, Paris, France, 2014.

Y. Nishi and T. Inagaki. 2017. Performance and Flow Field of a Gravitation Vortex Type Water Turbine. International Journal of Rotating Machinery Volume 2017, Article ID 2610508, 11 pages 